\title{
Aboio: Simetrias entre o Vaqueiro e Boi
}

\author{
Janaína Welle*
}

Resumo: O presente artigo tem por objetivo refletir sobre a animalidade e suas representações no cinema a partir da análise das relações estabelecidas entre o homem, o boi e a câmera no documentário Aboio (2005), de Marília Rocha.

Palavras-chave: animal; animalismo; meio ambiente; ecologia; Aboio.

Resumen: Este artículo tiene como objetivo reflexionar sobre la animalidad y sus representaciones en el cine a partir del análisis de las relaciones entre el hombre, el buey y la cámara en el documental Aboio (2005), de Marília Rocha.

Palabras clave: documental; animal; animalismo; medio ambiente; ecologia; Aboio.

\begin{abstract}
This article aims to reflect on the animalism and its representations in film from the analysis of the relations between man, the ox and the camera in Aboio documentary (2005), by Marília Rocha.

Keywords: documentary; animal; animalism; environment; ecology; Aboio.
\end{abstract}

Résumé: Cet article vise à réfléchir sur l'animalité et ses représentations au cinéma en se fondant sur l'analyse des relations entre l'homme, le bœuf et la caméra dans le documentaire Aboio (2005), de Marília Rocha.

Mots-clés: documentaire; animal; animalité; environnement; écologie; Aboio.

Aristóteles concebe o homem como um animal racional, esta definição separa e distancia o homem dos outros animais não humanos e o expulsa, em certa medida, do mundo da animalidade. Os homens seriam os únicos animais a guiar suas vidas a partir de referências éticas, religiosas, morais, políticas... utilizando sua racionalidade como baliza para suas ações. Esta racionalidade o eleva em relação aos outros animais e relega estes ao lugar de um não humano genérico, desprovido das características humanas como racionalidade, linguagem e consciência. Este distanciamento entre os humanos e os animais não humanos acaba por produzir uma assimetria nas relações entre as espécies e fortalece o paradigma da dicotomia entre natureza e cultura.

* Documentarista. Mestre em Multimeios pela Unicamp e em Antropologia Visual, pela Universidade Autônoma de Barcelona. Pesquisadora Voluntária do Laboratório Terra Mãe/NEPAM-Unicamp, 13083-970, Campinas, São Paulo, Brasil. E-mail: wellejanaina@gmail.com

Submissão do artigo: 07 de março de 2016. Notificação de aceitação: 12 de setembro de 2016 . 
Indícios históricos e arqueológicos nos mostram que a representação dos animais pelo homem é muito antiga. Os desenhos e pinturas rupestres foram as primeiras formas de representar e plasmar a vida nas rochas. Podemos apreender desses registros a grande importância que os animais sempre exerceram para os grupos humanos e a necessidade de fixar essa relação produzindo narrativas através das imagens. Com o cinema não é diferente, o animal sempre esteve presente nos registros cinematográficos, a começar pelos seus primórdios com a publicação de Animal Locomotion, uma coleção de 781 placas fotográficas compostas por mais de 20.000 imagens realizadas por Edward Muybridge em 1887, nas quais decompõe o movimento biomecânico de homens, mulheres, crianças, animais domésticos e selvagens. O trabalho de Muybridge dialoga com a obra La machine animale, de 1873, escrita por Étienne-Jules Marey, que contém diversos gráficos e ilustrações sobre o movimento dos seres vivos. Em 1882 Marey desenvolveu a cronofotografia, um fuzil fotográfico capaz de tirar 12 fotografias sequenciais por segundo e realizou inúmeros experimentos com homens, mulheres e diversos outros animais. Ambos os trabalhos são importantes contribuições para o estudo do movimento biomecânico dos animais e são as bases para o desenvolvimento do cinema.

Em 1897 Louis Lumière exibe na França o filme Le déjeuner du chat que mostra um gato tomando leite em um prato deixado por uma criança que o afaga. É a relação estabelecida entre um animal domesticado e uma criança. No âmbito do documentário, grandes realizadores como Flaherty, com produções como Nanook of the North, de 1922 e Lousianas, de 1948, e Jean Rouch com Bataille sur le grandfleuve, de 1951-1952, Les Maîtres fous de 1953 e La chasse au lion à l'arc, de 1965, filmaram modos de vida em sua maioria não ocidentais e a relação dessas sociedades com os animais (Fieschi, Lacoste e Tort, 1996).

Assim, podemos constatar que o traço animal está inscrito no cinema desde suas origens, mas não apenas como objeto de registro. Conforme elucida Scott MacDonald (2012), ecocrítico que desenvolve seu trabalho a partir de filmes experimentais que ele reconhece como ecocinema, resquícios de animais estão inseridos na matéria mesma do suporte fílmico. O autor afirma que o cinema:

(...) encapsula a maneira como a vida moderna e o mundo natural estão imbricados: os sais de prata fotossensíveis que criam uma imagem visível quando expostos à luz são suspensos em uma fina camada de gelatina, sendo o colágeno um de seus principais ingredientes. O colágeno é produzido pela fervura dos ossos e tecidos animais. A celuloide, a base sobre a qual a emulsão é disposta em camadas, é feita de celulose. Isto é, a "vida" que nós vemos em movimento na tela é um espécie de re-animação da vida vegetal e animal 
no interior do aparato mecânico/químico do cinema tradicional” (Macdonald, 2012: 18, tradução nossa). ${ }^{1}$

Tanto a vida animal quanto a vida vegetal compõem, literalmente, a película cinematográfica, tanto em sua constituição material quanto nos registros impressos na mesma. É interessante retomar aqui as primeiras experiências de Muybridge e Marey que decompõem o movimento de animais humanos e não humanos; seu mecanismo fotográfico utiliza imagens fixas sequenciais de um animal em deslocamento que, quando exibidas em determinada velocidade, dão a impressão de movimento. Este mesmo mecanismo usa como suporte material uma película que contém componentes provenientes de outras vidas.

Sempre que o homem representa o animal ele representa, em certa medida, a si mesmo. Há uma variabilidade na representação do homem, ora em oposição, ora em convergência com outras espécies animais. É importante refletir sobre as simetrias e assimetrias entre animais humanos e não humanos. O questionamento da atribuição de valores ou direitos diferentes entre animais a depender de sua espécie é trazido de maneira mais clara com a publicação em 1975 do livro Animal liberation, de Peter Singer. O autor desenvolve o conceito de especismo, definido como o tratamento diferenciado entre espécies e colocando o homem em uma relação de poder diante de animais não humanos que muitas vezes são explorados e mal-tratados. O livro citado apresenta as bases filosóficas fundadoras do movimento animalista levantando a discussão sobre o status moral dos animais. Singer parte de uma perspectiva filosófica utilitarista e afirma que todos têm direito à mesma consideração moral, independente de família, raça, nação ou espécie. Todos os seres com capacidade de sentir conscientemente prazer ou sofrimento, ou seja, todos os seres senscientes, merecem a mesma consideração moral. Suas proposições, apesar das críticas e superações, possuem grande influência no movimento animalista até os dias de hoje.

O ecocrítico Greg Garrard (2006) sistematizou como a literatura, em especial a anglo-saxônica, vem trabalhando os temas ecológicos ao longo do tempo. $\mathrm{O}$ autor chama atenção para a representação dos animais concebendoa como uma categoria de análise. Ele afirma ainda que a publicação de Singer, já citada, foi o grande marco acerca da representação animal por trazer à tona o também citado conceito de especismo e defender o princípio de igualdade

1. "(...) encapsulates the way in which modern life and the natural world are imbricated: the light-sensitive silvers salts that create a visible image when exposed to light are suspended in a thin layer of gelatin, one of the chief ingredients of which is collagen. Collagen is produced by boiling the bones and tissues of animals. Celluloid, the base on which the emulsion is layered, is made from cellulose. That is, the "life" we see moving on the screen is a kind of re-animation of plant and animal life within the mechanical/chemical apparatus of traditional cinema." (Scott MacDonald, 2012:18) 
entre as espécies, já que o sofrimento humano não deve ser mais importante que o de outro animal. Além de Animal liberation, Garrard menciona também a obra da filósofa Mary Midgley, Animals and why they matter, de 1983, que propõe restringir o princípio de igualdade entre espécies afirmando que existem situações onde os interesses humanos estão acima do de outras espécies (Garrard, 2006: 193). A autora critica o antropomorfismo, ou seja, a atitude de atribuir características humanas, como o desejo de liberdade, aos animais.

Garrard pontua ainda algumas diferenças entre o movimento pela libertação dos animais, que exige consideração moral no limite do senciente, isto é, dos animais que percebem o mundo pelos sentidos, e o movimento ambientalista, que exige consideração moral em relação a coisas inanimadas como rios e montanhas e presume que a dor e o sofrimento são partes da natureza. Existe ainda uma divisão entre duas categorias de animais não humanos: animais domésticos e animais selvagens. Geralmente o movimento de libertação dos animais levanta questões relacionadas aos animais domesticados, seja de estimação ou de exploração. Os ecocríticos usualmente têm a tendência de chamar atenção para os animais selvagens, pois eles teriam um grande potencial espetacularizante em nossa sociedade:

Para a maioria dos leitores modernos, não é o jardim zoológico, mas sim o documentário, ou filme sobre a vida selvagem, que molda predominantemente suas percepções dos animais selvagens. A crítica esclarecida do modo como essas produções moldam nossas idéias talvez seja a maneira mais importante de aumentarmos nossa compreensão ecocrítica, indo além do âmbito da literatura. (Garrard, 2006: 213)

Filmes e documentários sobre a vida selvagem fizeram grandes contribuições para campanhas ambientais. Mas é importante que a relação do espectador com a vida selvagem não se reduza simplesmente a um engajamento sensorial, intelectual e político; a uma experiência somente visual, que vem distorcida pela sua ênfase em eventos espetaculares, como caçadas na luta pela sobrevivência. A demanda por espetáculo tende a levar à valorização da predação, intensificado pela trilha sonora empolgante e pela profusão de imagens com o tempo dilatado ou acelerado, similares a um filme de suspense ou ação (Garrard, 2006: 214).

Jennifer Ladino (2012) se apropria das proposições de Donna Haraway para conduzir seu olhar sobre as representações dos animais em documentários. Haraway, em sua obra When species meet (2007), visa a esfumaçar as fronteiras binárias entre humano e não humano, entre animal doméstico e animal selvagem. A autora afirma que animais humanos e não humanos são parceiros que compartilham do mesmo mundo, são agentes que co-evoluem no mesmo ambiente. Em outras palavras, são espécies de companhia. Ladino 
afirma que em muitos documentários o que vemos é uma câmera especista, ou seja, uma câmera que privilegia o olhar antropocêntrico, vê os animais através dos olhos humanos, distorcendo seus comportamentos através de uma lente social que é repleta de expectativas ideológicas e de gênero, retratando-os como seres humanos. Frequentemente a perspectiva cinematográfica especista reduz o comportamento animal a uma caricatura do comportamento humano projetado em um antropomorfismo exacerbado.

Ladino busca identificar as escolhas éticas e estilísticas que determinam uma câmera especista e também quais as táticas para descentralizar esse olhar, tais como:

(...) permitindo que os animais humanos e não humanos co-habitem o espaço cinematográfico; mostrando animais não humanos "protegendo-se"; minimizando (ou desestabilizando) a linguagem humana e incluindo cenas zoomórficas e comentários que lembrem aos espectadores humanos nossa própria animalidade. (Ladino, 2012: 131, tradução nossa). ${ }^{2}$

Ladino afirma que precisamos descobrir os animais no ambiente habitado pelos humanos e em nós humanos como parte da pluralidade. Sugere que a comunidade acadêmica amplie seu corpus de textos ambientais para além dos textos de "natureza selvagem"; argumenta que os filmes experimentais, por exemplo, têm um grande potencial cinematográfico para alterar a consciência hoje predominante.

O já citado ecocrítico Scott MacDonald (2012) trabalha com ecocinema experimental. Ele afirma que esse cinema englobaria filmes opostos ao ritmo histérico da mídia comercial, principalmente da publicidade, e sua função não seria produzir narrativas pró-ambientais no estilo Hollywood, ou no estilo documentário convencional, ainda que, segundo ele, os documentários possam alertar-nos para questões ambientais. O crítico afirma que este grupo de filmes:

(...) oferece à audiência uma representação do mundo natural dentro da experiência cinematográfica que modela a paciência e a atenção - qualidades da consciência cruciais para uma apreciação profunda e um contínuo comprometimento com o ambiente natural (Macdonald, 2012: 19, tradução nossa). ${ }^{3}$

2. "(..) allowing human and nonhuman animals to co-inhabit the cinematic space; showing nonhuman animals "watching back"; minimizing (or destabilizing) human language; and including zoomorphic footage and commentary that remind human viewers of our own animality." (Ladino, 2012: 131).

3. “(...) offers audiences a depiction of the natural world within a cinematic experience that models patience and mindfulness - qualities of consciousness crucial for a deep appreciation of and an ongoing commitment to the natural environment." (Macdonald, 2012: 19) 
A partir dessa breve apresentação das questões animalistas atuais iremos voltar nosso olhar para a representação das relações entre homens e bois no documentário Aboio (2005), de Marília Rocha.

O aboio é o canto das palavras que os vaqueiros da região da caatinga de Minas Gerais, Bahia e Pernambuco utilizam para tanger o gado. Como uma onomatopéia musicada, conversam com os bois como se falassem uma mesma língua, como se tivessem criado uma linguagem própria que dialoga e acaricia ao mesmo tempo. Este canto, tão característico dessa região, aparece na obra de Guimarães Rosa, Mario de Andrade e Câmara Cascudo. E foi nessa literatura que a documentarista Marília Rocha se inspirou para sua pesquisa que resultou em seu primeiro longa.

O documentário é um resgate das tradições do aboio através das memórias que os vaqueiros trazem consigo. É um filme feito com imagens do presente, mas que remetem, em diversos momentos, a um tempo passado, a memórias reatualizadas. Aboio é composto por imagens sem um tempo determinado, nos dando a sensação de tempos entrecruzados, em um lugar onde a memória se atualiza e se transforma em presente. É composto por dois tipos de imagem, de um lado temos registros em preto e branco, granulados, gravados em super 8 e que trazem uma aura onírica, de resgate e, por outro lado, dialogando com estas imagens oníricas, temos grande parte do filme gravado em suporte digital, colorido, que remete ao presente, às mudanças e reconfigurações da tradição do aboio que estão em curso. Aboio é o resgate de uma tradição que aos poucos está se perdendo em uns e se reconfigurando em outros de seus protagonistas; se fortalecendo junto aos que tangem por prazer, já não mais por profissão, e na memória dos que viveram, viram ou ouviram o cantar do aboio.

$\mathrm{O}$ documentário está dividido em três atos iniciados por um símbolo. $\mathrm{O}$ primeiro se assemelha a uma ferradura, o segundo se inicia com uma espécie de vaqueiro, e o terceiro com o símbolo do infinito. Ou seja, o boi, o vaqueiro e o que está por vir. Os personagens não são apresentados pelos nomes, inclusive há depoimentos em off em que não vemos em nenhum momento a imagem do personagem nem sabemos quem ele é. Mas isso não é o que realmente importa, o que importa é a sua fala, sua ação, seu corpo, seus gestos, a paisagem em que está inserido, aquilo que a experiência sensível revela. Marília Rocha faz, em Aboio, uma ligação entre a cultura popular do aboio e a música popular por meio de entrevistas com artistas que usam referências do universo dos vaqueiros, como Naná Vasconcelos, Elomar e Lirinha. A palavra do vaqueiro rima com a dos poetas e músicos. Tanto no aboio quando na trilha do filme a linguagem dos vaqueiros se torna música. Os quatro elementos da natureza estão muito presentes, tanto em imagens quanto em sons. A terra árida da 
caatinga, o fogo que dança em câmera lenta, o céu que rodopia sobre as cabeças e a água da chuva que cai generosa. Esses elementos intensificam a ligação do vaqueiro com a natureza do sertão.

O feminino também encontra reverberações no universo masculino do aboio. Além do olhar da cineasta, única mulher na equipe que contava com outros três integrantes, a presença feminina ganha relevância em duas passagens. A primeira na história que nos é contada por um vaqueiro sobre uma mulher que chega com uma criança nos braços e, para salvar seu filho do ataque de um boi, deita em cima da criança para protegê-la, saca um punhal e mata o animal. A segunda no depoimento de outro vaqueiro que encontrou um aboiador de voz fina que depois descobriu ser uma mulher, esposa de um companheiro, que "boiava que nem a gente". Cabe aqui um paralelo com Diadorim, personagem mítica do grande sertão de Guimarães Rosa.

O animalismo inerente ao aboio é reforçado pela composição imagética e sonora do filme. No aboio a relação estabelecida entre o vaqueiro e o boi é central. É interessante perceber a construção dessa relação no filme. O olhar da câmera para o boi no documentário em questão é horizontal, recupera a simetria entre homem e boi, pois ambos são animais e compartilham do mesmo mundo-ambiente; eles se acompanham, conversam, têm uma relação de companhia, respeito e afeto. Para trabalhar com esse olhar trazido por Marília Rocha, propomos aqui o conceito de câmera empática em contraposição à câmera especista delineada por Ladino (2012). Por câmera empática entendemos uma câmera que olha para todas as outras espécies animais e para todos os organismos vivos que partilham da mesma atmosfera, com simetria, colocando em um mesmo patamar de igualdade todas as espécies. A câmera se transforma no vaqueiro em simbiose com seu cavalo que tangue o gado, se comunica com o boi em uma relação empática, subvertendo o olhar especista assimétrico. A documentatista apresenta sua postura empática já no primeiro depoimento no qual escutamos uma voz masculina que recorda sua infância e afirma que foi criado "(...) quase como os próprios bichinhos no mato, eram uns bichinhos fugindo de outros." A simetria entre animais humanos e não humanos na vida do vaqueiro se inicia na infância, onde partilham do mesmo ambiente, crescem e se desenvolvem juntos, são animais compartilhando a vida.

A relação próxima entre o vaqueiro e o boi perpassa todo o filme, assim como perpassa toda a vida do vaqueiro; ela está em seu imaginário, presente na poesia gravada em vinil do Boi Veneno, nos diversos "causos" contados e, principalmente, no próprio aboio. Seu canto é constituído em grande parte por onomatopeias que imitam os sons produzidos pelos bois criando uma linguagem em comum que propicia a comunicação entre eles. É um vínculo musical 
estabelecido entre o homem e o boi. Há um depoimento que revela a conexão entre esses dois animais. $\mathrm{O}$ vaqueiro afirma que:

[O] aboio é uma cantoria, é uma correria, é uma oração, é uma benção, é um carinho que ele dá ao boi. [...] Quer dizer, ele não precisa bater no touro, com o canto, com a cantoria, é uma espécie de carinho para guiá-lo a voltar para casa ou para sair de casa para passear. Então isso, esse lado assim é muito bonito.

Ou seja, a conversa entre o homem e o boi é cordial, afável, e com ela não é preciso o uso da força física para o manejo do rebanho. Além disso, o vaqueiro afirma ainda que existem dois tipos de aboio, um para chamar e outro para tanger; em seguida canta os dois aboios para mostrar a diferença entre eles e diz que o gado diferencia as melodias. Depois de três ou quatro meses de convivência a relação entre ambos se torna muito próxima, o vaqueiro conclui dizendo que após esse período juntos o gado ficava tão sabido que só faltava falar.

A comunicação entre homens e bois é enfatizada em outros cinco momentos. Os dois primeiros em relação à nomeação do gado e dos bezerros, cada boi tem seu nome e responde a ele quando chamado, segundo o vaqueiro "é que nem gente". No caso dos bezerros eles têm o mesmo nome da mãe, quando chamam a vaca vem seu bezerro junto que atende pelo mesmo nome. $\mathrm{O}$ vaqueiro reconhece os bois por seus respectivos nomes e os bois reconhecem os vaqueiros pelo faro, como afirma já no fim do filme um dos vaqueiros. Outro momento interessante, bastante representativo da relação empática entre vaqueiro e boi, é a capacidade do vaqueiro de decifrar o que o gado está fazendo pelo simples repicar dos sinos. Um dos entrevistados tem um sino nas mãos e toca a melodia que o boi faria em certa ocasião: "assim é quando a vaca está amamentando o bezerro, esse é o som quando o gado está bebendo água, assim é quando ele está correndo". Em quarto lugar sublinhamos a narração de um dos vaqueiros sobre as "brigas" e "discussões" que os bois têm entre eles. Ele narra a disputa entre os bois imitando os sons da briga. E, por último, a comunicação através das onomatopeias, uma espécie de linguagem criada pelo vaqueiro, inspirada no mugido dos bois, que consegue estabelecer uma comunicação entre ele e o animal. Há um depoimento em off muito elucidativo que diz: "A onomatopeia tem muito mais força, porque é um mistério que só o boi entende." Todos os momentos elegidos mostram a comunicação entre homem e boi, calcada sempre na dimensão sonora que vai além do próprio aboio, consolidando a representação da relação empática estabelecida entre as espécies pelo filme.

A dimensão etnográfica de Aboio é pungente, recupera a memória dos vaqueiros, os "causos", como era o tanger do gado nas décadas passadas na re- 
gião, a herança cultural da região. Resgata o modo de vida sertanejo, a bravura do vaqueiro, o conhecimento do ambiente, desde onde encontrar água e alimento até como matar as bicheiras do gado com reza e algumas folhas. Apresenta o cotidiano de um vaqueiro que come com o sol nascendo e só volta a comer quando o sol se põe. Antigamente não havia cercas delimitando as propriedades, o gado ficava solto por entre a vegetação, o vaqueiro conduzia a boiada por meses até sua comercialização. Retoma também a tradição da "Pega de Boi no Mato", onde os vaqueiros encourados perseguiam um ou mais bois soltos em meio à vegetação catingueira, tradição existente desde meados do século XIX. Cita também, no filme, as influências mouras na toada do aboio. O documentário faz uma etnografia desse canto, da vida sertaneja, suas memórias e transformações atuais.

O documentário, para além de fazer essa etnografia a partir da história oral dos vaqueiros e do registro de seu aboiar, também ressignifica e reelabora o aboio e apresenta uma nova sonoridade, um aboio musicado. A documentarista segue a indicação de um dos vaqueiros que afirma que não devemos olhar para o aboio com o sentimento de saudades como se tivéssemos perdendo algo, pois, na verdade, as coisas estão se transformando. Neste sentido o filme traz um aboio reelaborado que absorve, além das onomatopeias musicadas, o mugido do gado, o estalar dos galhos, os sinos dos bois, o assovio do vento; mesclados eles compõem outra melodia, uma nova música, reinventando e atualizando à sua maneira a tradição do aboio. Um depoimento em off nos faz ouvir que: "[Antes o] aboiador fazia o verso e aboiava. Hoje não, não tem o aboio, só é o verso." Diante do verso sem sons a diretora se viu impelida a resgatar e construir uma nova musicalidade.

A dimensão empática do filme mais incisiva é a corpórea. Homem e boi estão intimamente ligados por sua condição animal. O documentário rompe com o especismo apresentando uma câmera empática que é, ela mesma, um personagem, um vaqueiro-câmera, que cavalga por entre os galhos secos da caatinga tangendo o gado. Homem e boi estão em posições simétricas, em uma igualdade de lugar, de olhar e de valor. Há, no filme, um constructo muito significativo que atesta a proposição de uma câmera empática, o paralelismo corpóreo entre vaqueiro e boi. Existem inúmeras passagens onde a câmera foca partes do vaqueiro ou do boi, seus olhos, partes dos rostos, partes dos corpos; essa analogia aparece de forma reiterada ao longo do filme. É uma maneira de colocar ambos em equivalência, em correspondência de valor, em equidade. Assim fazendo, estabelece um paralelismo entre homem, boi e câmera. 

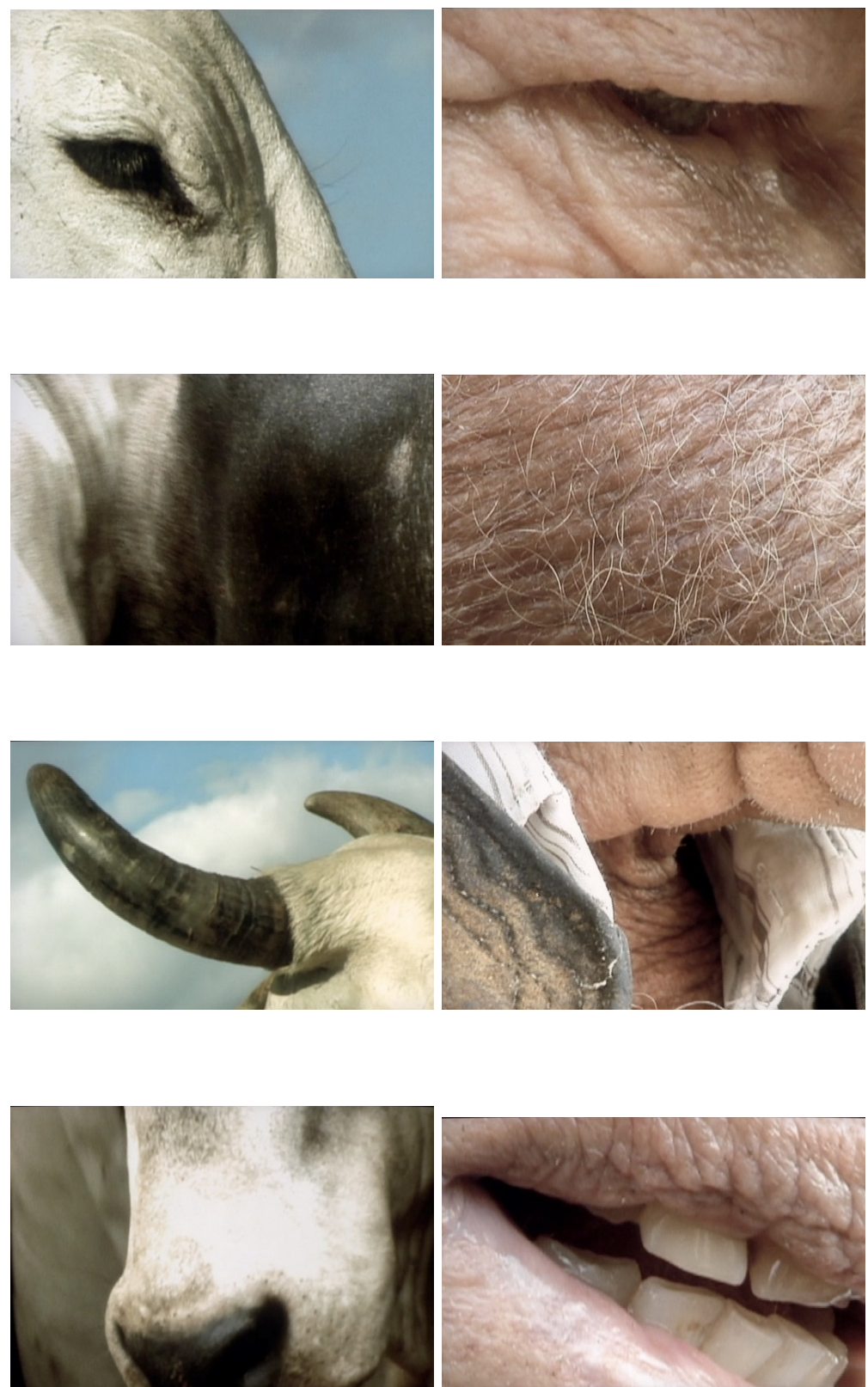

O documentário aproxima o animal humano e não humano visualmente, narrativamente e experimentalmente. Aboio é todo ele articulado a partir de sinestesias, de mesclas de sensações e provocações dos sentidos. Encontramos aqui outro elemento da postura empática: todos os seres senscientes, ou 
seja, aqueles que, como já vimos, percebem o mundo através dos sentidos, e, portanto, são capazes de sentir prazer ou sofrimento, merecem a mesma consideração moral. O filme propõe uma experiência sinestésica através da relação estabelecida entre o vaqueiro-câmera e o gado. Assim, proporciona ao espectador uma aproximação com o mundo dos vaqueiros que se comunicam com o gado cantando palavras através da própria experiência do aboiar, de tanger o gado, de cavalgar por entre os galhos secos, através do vaqueiro-câmera. A experiência quase sinestésica de ouvir, ver, perceber e sentir a relação homemboi aproxima o cidadão urbano comum ao universo dos vaqueiros que tangem o gado acariciando os bois com seu canto. Ora de maneira mais onírica, ora de maneira mais etnográfica, ora de maneira mais dialógica nos depoimentos presentes no filme, nos acercamos de uma relação homem-boi onde a poesia é a linguagem da comunicação entre os vaqueiros e o gado, assim como na relação construída entre o vaqueiro-câmera e o seu público. A linguagem utilizada nas comunicações entre homem-boi e homem-homem para dentro e para fora do filme é poética, muito plástica e essencialmente sonora.

A última cena do filme se inicia com uma musica sobre a saudade:

Trazer de quem tem saudade/ É a saudade todo dia/ A saudade é tão ingrata que todo o dia maltrata/ Além de maltratar mata a quem não tem alegria/ Ela é maltratadeira além de ser matadeira/ Oh saudade companheira de quem não tem companhia.

É a saudade do aboio dos tempos antigos, mas a tradição existe no presente, recupera elementos ancestrais do passado, mas se atualiza a vive no presente, em constante movimento e reconfiguração. Essa é a metáfora do filme, a documentarista recupera o aboio antigo, mas o apresenta à sua maneira, com seu olhar, assim como o próprio aboio que segue seu próprio fluxo, não de extinção mas de reelaboração e reatualização constante pelos próprios vaqueiros. Como diz um depoimento, tudo no mundo, no instante mágico que nasce já começa a morrer, reiterando o ciclo da vida, da vida do homem, da vida do boi, da vida do aboio. Tudo e todos estão conectados. A cena continua com uma composição de imagens em Super-8, em preto e branco, bastante granuladas e de tom onírico onde vemos o sol que parece noite, carcaças de animais, as crianças brincando no açude, a paisagem árida e o vaqueiro desaparecendo em meio à poeira. O áudio é pautado por um grave que só é interrompido pelo riso das crianças. Marília Rocha termina seu filme com as grandes contradições do sertão, com as contradições presentes na vida: a vida e a morte, o frescor da infância feliz e a morte na terra áspera, a paisagem seca versus o açude. Essas contradições trazem a complexidade da vida e vão em sentido contrário a um binarismo dicotômico; se traduzem em um fundamento para se 
pensar a conjunção entre natureza e cultura e lançar um olhar empático entre as espécies, fortalecendo as simetrias entre os seres que compõem o mundo. Termina com um fade para o branco e ficamos somente com o som da chuva que cai dadivosa na caatinga. Reitera a vida, é a água quem traz a vida para a região, como se também pudesse regar o aboio, na carícia da natureza no chão árido do sertão. Pois como bem disse um vaqueiro: "Tudo na vida tem que ter agrado."

\section{Referências bibliográficas}

Barisone, L. (s.d.). Os últimos. Disponível em: http://www.mariliarocha.com/ wp-content/uploads/2008/10/Os-ultimos_Luciano_Barisone.pdf

Brasil, A. (s.d.). Quando as palavras cantam, as imagens deliram. Revista Cinética. Disponível em: http://www.revistacinetica.com.br/aboioandarilho .htm

Fieschi, J.-A.; Lacoste, P. \& Tort, P. (1996). L'animal écran. Paris: Centre Georges Pompidou.

Garrard (2006). Ecocrítica, Brasília: UNB.

Ladino, J. (2012). Working with animals: regarding companion species in documentary film. In S. Rust, S. Monani \& S. Cubbit (eds). Ecocinema theory and practice. New York: Routledge/AFI.

MacDonald, S. (2012). The ecocinema experience. In S. Rust, S. Monani $\&$ S. Cubbit (eds.). Ecocinema theory and practice. New York: Routledge/AFI.

Midgley, M. (1983). Animals and why they matter: a journey around the species barrier. Athens: University of Georgia Press.

Paranaguá, P. A. (s.d.). Aboio. Disponível em: http://www.mariliarocha.com/ wp-content/uploads/2010/01/ABOIO_paulo_antonio_paranagua.pdf

Pereira, L. A. (s.d.). Plural de bois. Disponível em: http://www.mariliarocha.c om/wp-content/uploads/2010/01/Plural_de_boi_Luis_Araujo_Pereira.pdf

Singer, P. (2010). Libertação animal: o clássico definitivo sobre o movimento pelos direitos dos animais. M. Winckler, M. B. Cipolla (Trads.). São Paulo, SP: WMF Martins Fontes.

\section{Filmografia}

Aboio. Direção: Marília Rocha. Brasil, 2005. DVD (73 min.), son., color. e preto e branco, português. 
Bataille sur le grand fleuve. Direção: Jean Rouch. França, 1951-1952. Película (33 min.), son., color., francês.

La chasse ou lion à l'arc. Direção: Jean Rouch. França, 1965. Película (90 min.), son., color., francês.

Le Déjuner du Chat. Direção: Louis Lumière. França, 1987. Película (1 min), mudo, preto e branco.

Les Maîtres Fous. Direção: Jean Rouch. França, 1953. Película (24 min), son., color., francês.

Lousiana Story. Direção: Robert Flaherty. EUA, 1948. Película (78 min), son., preto e branco, inglês.

Nanook of the North. Direção: Robert Flaherty. EUA, 1922. Película (79 min), mudo, preto e branco. 